\title{
RESEARCH BRIEF
}

\section{Engaging Pharmacy Students in Research Through Near-Peer Training}

\author{
Benjamin J. Lee, PharmD, ${ }^{a}$ Nathaniel J. Rhodes, PharmD, MSc, ${ }^{\text {b,c }}$ Marc H. Scheetz, PharmD, MSc, \\ Milena M. McLaughlin, PharmD, MSc ${ }^{\text {b,c }}$ \\ ${ }^{a}$ University of California Irvine Health, Orange, California \\ ${ }^{\mathrm{b}}$ Midwestern University, Chicago College of Pharmacy, Downers Grove, Illinois \\ ${ }^{\mathrm{c}}$ Northwestern Memorial Hospital, Chicago, Illinois \\ Submitted February 1, 2017; accepted June 19, 2017; published November 2017.
}

Objective. To describe the implementation of a near-peer training model within a student research program.

Methods. A near-peer training model was implemented in a pharmacy student research program to promote development of effective teaching skills and research competencies. Under the supervision of a research mentor, senior learners precepted junior learners in various aspects of translational research. A three-step teaching process was employed throughout the experience in which junior learners performed an assigned task, senior learners provided guidance and mentorship, and research mentors provided feedback for improvement.

Results. A total of 43 pharmacy trainees have participated in the student research program; each year of involvement now averages 15 to 18 students. The program has been responsible for almost 100 poster presentations at national meetings and more than 20 manuscripts in peer-reviewed journals. Funding through intramural grants and scholarships to compensate for conference expenses and other functions has also been awarded.

Conclusion. Near-peer teaching supports a tiered-research model under the supervision of a research mentor. For health care systems and colleges of pharmacy with established research programs or those seeking to implement new programs, near-peer teaching appears to be a promising strategy to promote the development of research competencies in pharmacist trainees.

Keywords: research training, near-peer teaching, pharmacy student

\section{INTRODUCTION}

Pharmacy practice has evolved from traditional dispensing services into the high-skill realms of patient-level medication optimization and population-level health policy implementation. ${ }^{1,2}$ These skills require that the practitioner possess a strong knowledge of both evidence-based medicine and clinical acumen. Importantly, the integration of evidence-based medicine into the clinical decision-making process requires pharmacists to effectively interpret, utilize, and communicate research findings. These skills can be honed through the creation and dissemination of knowledge by conducting clinical research. ${ }^{3}$ Therefore, the development of critical thinking skills and clinical competence through research instruction for pharmacist trainees has been identified as essential for the advancement of the pharmacy profession. ${ }^{4,5}$

Corresponding Author: Benjamin J. Lee, University of California Irvine Health, Department of Pharmacy, 101 The City Drive South, Orange, CA 92868. Tel: 714-456-6337. Fax: 714-456-5998. E-mail: benjam19@uci.edu
To ensure that future generations of pharmacists are prepared with these skills, numerous organizations including the American College of Clinical Pharmacy (ACCP), the Accreditation Council for Pharmacy Education (ACPE), and the American Association of Colleges of Pharmacy (AACP) have called for more researchbased scholarship in pharmacy curricula. ${ }^{5-8}$ In a 2016 issue of Pharmacotherapy, Deal and colleagues highlighted the importance of providing such experiences for pharmacy students and residents. ${ }^{9}$ As described in the article, early engagement in research activities provides trainees with numerous immediate and long-term benefits including professional growth, development of critical thinking and time management skills, and proficiency in research collaborations. It also engenders a systematic cognitive approach to solving challenges encountered in health care settings.

Thus, early research engagement can enhance scholarly skills of pharmacy trainees and provide better preparation for future practice; however, few opportunities for in-depth, translational research are known to exist in 


\section{American Journal of Pharmaceutical Education 2017; 81 (9) Article 6340.}

current pharmacy curricula. ${ }^{10}$ Evidence from a 2007 survey revealed that less than $20 \%$ of pharmacy schools required completion of a research project or had a research program available to students. ${ }^{10}$ Several factors are cited as potential obstacles, most notably faculty time constraints, limited knowledge of the publication process, and lack of mentorship. ${ }^{9}$

We developed a student research program utilizing a near-peer/peer-assisted modality (individuals close to oneself, but not at the same level of experience in the training continuum) to overcome several of the barriers to research instruction. ${ }^{3,9}$ Key advantages to this model include opportunities to reinforce and augment one's own learning and enhanced capacity for teaching nearpeers how to conduct research while also promoting selfreflection and deeper learning. ${ }^{11}$ Adoption of near-peer teaching provides opportunities for experienced students to partake in research-related activities at a high level of engagement. This brief describes the implementation of a near-peer training model within a student research program.

\section{METHODS}

Beginning in the spring of 2009, a student research collaboration between Midwestern University, Chicago College of Pharmacy (MWU CCP) and Northwestern Memorial Hospital (NMH), an 897-bed academic medical center in Chicago, IL was established. ${ }^{3}$ The first two years characterized the developmental phase of our program during which the infectious diseases pharmacist and fellow selected several students to assist with data collection and presentation of research findings. Once the program structure was solidified and research mentors recruited, the program flourished and rapidly expanded in size over the next two years with student involvement increasing nearly tenfold with the production of numerous academic contributions. This defined the growth phase of our research program. By 2014, continued interest generated by repeat second- and third- year pharmacy students resulted in an intermingling of trainees with varied skill levels, setting the foundation for a tiered near-peer learning experience during the maintenance phase.

Analogous to the layered learning model for graduate students and pharmacy trainees, research mentors guide senior learners in effective preceptorship who then advise junior learners in completing the various components of research. Experienced students, having completed at least one year of research training along with Collaborative Institutional Training Initiative (CITI) certification, are eligible to become senior learners. These senior learners coordinate new student orientation, assist with training exercises, and manage group communications (eg, emails and meetings). Those interested in advancing their research skills through teaching are identified as senior learners and are assigned with one or more new students, or junior learners, to a new research project proposal. Within the context of our near-peer training program, junior learners are pharmacy students (professional years I to III) with minimal to no research experience who have been invited to participate in the program. Research mentors oversee the senior and junior learners. Research mentors are pharmacists and other health care providers employed through MWU or NMH who have submitted a research proposal.

A three-step process is applied throughout the research experience in which junior learners perform an assigned task, the senior learner oversees, gives guidance, and makes revisions, and the research mentor reviews the submitted research product and delivers feedback for improvement (Figure 1). This feedback relates to the research project as well as the mentoring ability of the senior learner. The process is repeated until the research product is finalized. This practical hands-on mentoring experience in methodology and writing skills of junior learners by senior learners provides an opportunity for self-reflection in both groups.

The research program operates year-round, with a new cycle beginning each spring quarter. To support student activities, a variety of mechanisms exist such as elective course credits (offered during the academic year) and financial compensation via intramural grants or Federal Work Study Programs. In the spring quarter, a comprehensive literature review is conducted to establish the research question. Next, senior and junior learners are charged with defining the primary and secondary outcomes, significant endpoints, study variables, and methodology for data collection in preparation for submission of an Institutional Review Board (IRB) application. This preliminary work is performed over the 3 months before students are invited to $\mathrm{NMH}$ to collect data. A series of educational presentations are provided during the summer months when the bulk of data collection and analysis is taking place.

Presentation topics include introductory biostatistics, study design and methodology, and basics in data collection (eg, extraction of clinical, laboratory, and medication-related data, etc.). Research students are also engaged in other interdisciplinary educational opportunities (eg, shadowing clinical pharmacists on rounds, attending advanced rotational student journal clubs, and participating in patient case discussions). Upon completion, research students collate collected data and perform statistical analyses to interpret their results. Over the next two months, senior learners work with their junior learners to analyze research findings, and begin preparing findings for dissemination. 


\section{American Journal of Pharmaceutical Education 2017; 81 (9) Article 6340.}

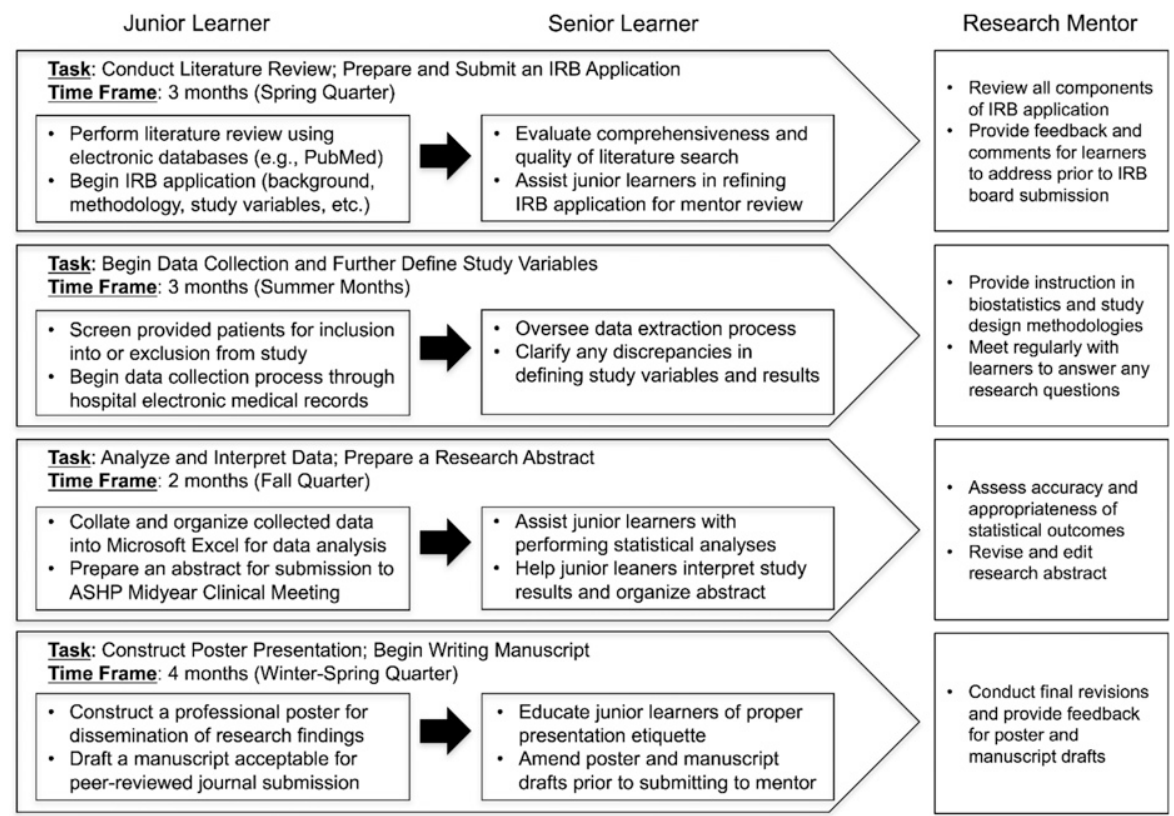

Figure 1. Near-Peer Teaching Model.

\section{RESULTS}

Since the inception of the program, a total of 43 pharmacy students have participated in our research program. Student involvement increased nearly tenfold from two in 2009 to 16 in 2013, with each following year averaging 15 to 18 students. To provide a high-quality research experience and adhere to hospital regulations, student invitations for on-site activities at NMH are restricted to less than 20 each year.

Our research program yielded 46 posters at national meetings and seven publications in peer-reviewed journals in its first four years. ${ }^{3}$ From 2014 to 2017, during which near-peer teaching practices were adopted, research dissemination efforts continued with students contributing to 51 posters at national conferences and co-authoring 20 manuscripts with research mentors. Overall, pharmacy student engagement produced 97 poster presentations and 27 publications in peer-reviewed journals. Lastly, research students are encouraged to apply for funding to compensate for conference expenses and other functions through intramural grants and scholarships. Students have successfully competed for scholarships, fellowships, and travel awards, with over $\$ 58,000$ in funds having been dispersed to date.

\section{DISCUSSION}

Our near-peer research program has allowed students to be involved in research experience on a high level. This model allowed us to overcome several barriers that were noted by Deal and colleagues. ${ }^{9}$ Rather than being limited by time available with one research mentor, senior learners are able to oversee multiple junior learners and triage issues and questions. This expands opportunities for involvement on several projects and working with different groups of students. Instead of relying on research mentors to provide step-by-step instructions, the senior learner becomes the direct supervisor of the junior learners' day-to-day progress. Because of the tiered nature of the experience, multiple students are available to complete a project if a senior learner leaves the program due to other obligations. When students are preparing for dissemination of their findings, the senior learners provide preliminary feedback on posters and manuscript drafts.

Advocates of near-peer teaching attribute its success to "cognitive congruence" or sharing of a similar knowledge foundation. Senior learners are better able to understand difficulties encountered by junior learners and are capable of explaining concepts in a more appropriate manner. ${ }^{12}$ Senior learners benefit through these interactions by solidifying knowledge and reinforcing skills to attain a greater understanding of the topics they are teaching. Several studies evaluating near-peer teaching have also reported that social congruence is another fundamental component in the near-peer relationship. ${ }^{11,13,14}$ It has been suggested that students are more comfortable approaching their peers than faculty; specifically, they may feel more comfortable asking "simple" questions or when troubleshooting issues. ${ }^{13}$ By providing structured mentor-mentee relations, senior learners can develop a sense of accountability for their trainees, while junior learners can seek feedback in a lower-stakes environment. 


\section{American Journal of Pharmaceutical Education 2017; 81 (9) Article 6340.}

Furthermore, evidence suggests that the instruction of junior students positively impacts a senior student's facilitation and communication skills, which are crucial attributes for pharmacists practicing in any health care setting. 11,14

\section{CONCLUSION}

Near-peer teaching provides opportunities for applied learning and supports a tiered-learning model under the supervision of a research mentor. Importantly, this model of learning provides more opportunities for pharmacy students to obtain research experience and meet the increasing demands for patient-centered, evidence-based care. For health care systems and colleges of pharmacy with established research programs or those seeking to implement new programs, near-peer teaching appears to be a promising strategy to promote the development of research competencies in pharmacist trainees.

\section{REFERENCES}

1. Jarab AS, Alqudah SG, Mukattash TL, Shattat G, Al-Qirim T. Randomized controlled trial of clinical pharmacy management of patients with type 2 diabetes in an outpatient diabetes clinic in Jordan. J Manag Care Pharm. 2012;18(7):516-526.

2. Wishah RA, Al-Khawaldeh OA, Albsoul AM. Impact of pharmaceutical care interventions on glycemic control and other health-related clinical outcomes in patients with type 2 diabetes: randomized controlled trial. Diabetes Metab Syndr. 2015;9(4):271276.

3. McLaughlin MM, Skoglund E, Bergman S, Scheetz MH. Development of a pharmacy student research program at a large academic medical center. Am J Health Syst Pharm. 2015;72(21):1885-1889.
4. Fagan SC, Touchette D, Smith JA, et al. The state of science and research in clinical pharmacy. Pharmacotherapy. 2006;26(7):10271040 .

5. American College of Clinical Pharmacy, Lee MW, Clay PG, et al. The essential research curriculum for doctor of pharmacy degree programs. Pharmacotherapy. 2010;30(9):966.

6. Accreditation Council for Pharmacy Education. Accreditation standards and key elements for the professional program in pharmacy leading to the doctor of pharmacy degree. Standards 2016. www. acpe-accredit.org/pdf/Standards2016FINAL.pdf. Accessed December 16, 2016.

7. Leslie SW, Corcoran III GB, MacKichan JJ, Undie AS, Vanderveen RP, Miller KW. Pharmacy scholarship reconsidered: the report of the 2003-2004 research and graduate affairs committee. Am J Pharm Educ. 2004;68(3):S6.

8. Lee MW, Bennett M, Chase P, et al. Final report and recommendations of the 2002 AACP Task Force on the Role of Colleges and Schools in Residency Training. www.aacp.org/governance/ councildeans/Documents/FinalTaskForceReportResidencies.pdf. Accessed December 16, 2016.

9. Deal EN, Stranges PM, Maxwell WD, et al. The importance of research and scholarly activity in pharmacy training.

Pharmacotherapy. 2016;36(12):e200-e205.

10. Murphy JE, Slack MK, Boesen KP, Kirking DM. Researchrelated coursework and research experiences in doctor of pharmacy programs. Am J Pharm Educ. 2007;71(6):Article 113.

11. Solomon P, Crowe J. Perceptions of student peer tutors in a problem-based learning programme. Med Teach. 2001;23(2):181186.

12. Lockspeiser TM, O'Sullivan P, Teherani A, Muller J.

Understanding the experience of being taught by peers: the value of social and cognitive congruence. Adv Health Sci Educ Theory Pract. 2008;13(3):361-372.

13. Bulte C, Betts A, Garner K, Durning S. Student teaching: views of student near-peer teachers and learners. Med Teach. 2007;29(6):583-590.

14. Evans DJ, Cuffe T. Near-peer teaching in anatomy: an approach for deeper learning. Anat Sci Educ. 2009;2(5):227-233. 